\title{
Paget's Disease of the Breast
}

A dangerous imitator of eczema

"Paula Aguayo-Carreras, ${ }^{1}$ Laura Bonilla-García, ${ }^{2}$ Israel Pérez-López, ${ }^{1}$ Carlos Cuenca-Barrales, Jesús Tercedor-Sánchez

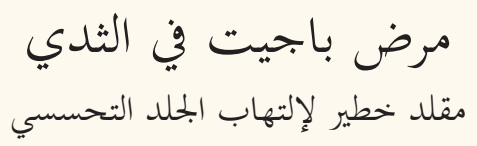

بولا أغويو-كاريراس، لورا بونيلا-غارسيا، إسرائيل بيريز-لوييز، كارلوس كنسا-بـاراليس، جيسوس ترسيدور-سانشيز

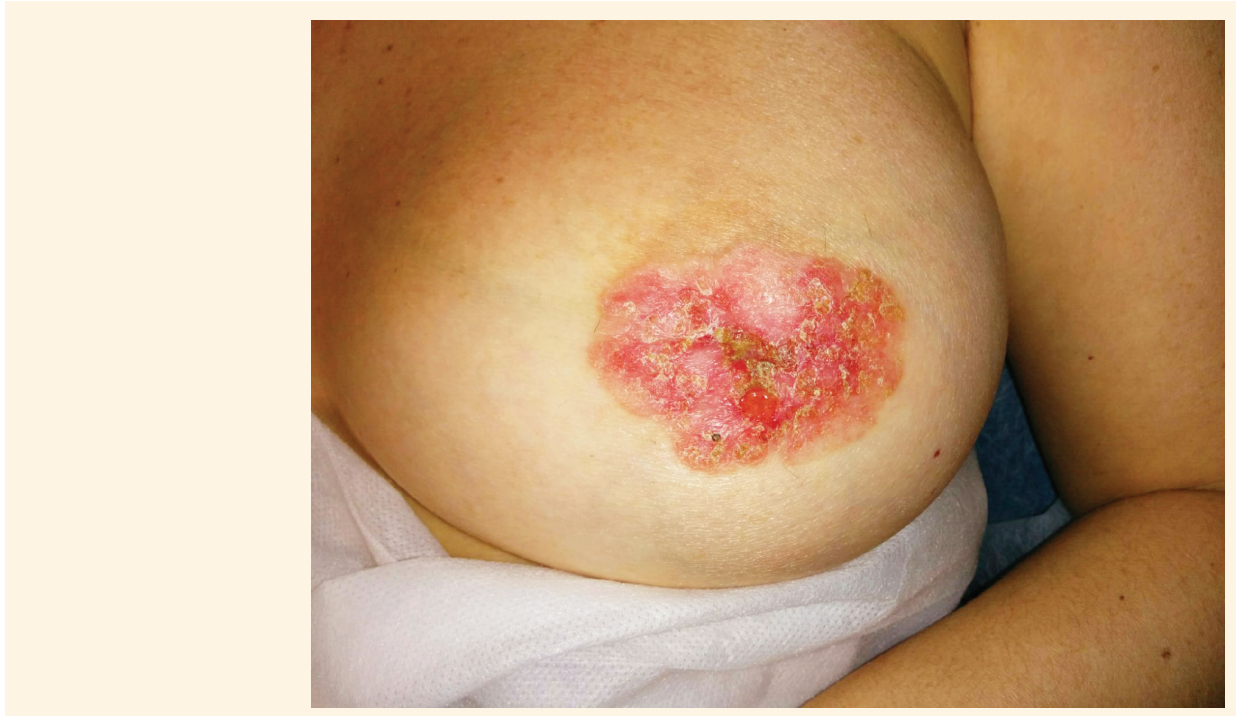

Figure 1: Photograph of an uninfiltrated erythematous plaque on the left breast of a 46-year-old woman with effacement of the areola-nipple complex.

A 46-YEAR-OLD WOMAN WITH NO PERSONAL or family history of cancer presented to the Department of Dermatology at the Complejo Hospitalario Universitario de Granada, Granada, Spain, in 2017 with an eczematous plaque in the areola of the left breast. The plaque had developed over the course of the past four years and was associated with stinging, itching and occasional suppuration. She had been previously treated with topical corticosteroids and antibiotics without improvement. A mammogram performed the previous year showed a small benign nodule of $8 \times 5 \mathrm{~mm}$ in diameter and a simple cyst of $5 \mathrm{~mm}$ in diameter in the right breast. There was no evidence of ductal ectasia or alterations at the left retroareolar level 1. A physical examination revealed an erythematous-squamous plaque of $4 \times 5 \mathrm{~cm}$ in diameter on the left breast without infiltration and with effacement of the areola-nipple complex [Figure 1].

No local lymph nodes were palpated. A cutaneous ultrasound showed hyperkeratosis of the epidermis with a hypoechoic area in the dermis with increased vascularisation. A large incisional biopsy confirmed a diagnosis of Paget's disease of the nipple with ductal carcinoma in situ. A quadrantectomy and selective sentinel node biopsy were performed, the latter of which was negative. The patient was subsequently monitored for the next three years without evidence of clinical recurrence.

\section{Comment}

Paget's disease of the breast is characterised by the intraepidermal infiltration of malignant glandular 
epithelial cells which usually unilaterally affects the nipple or areola and clinically simulates chronic eczematous dermatitis. ${ }^{1}$ Generally, the onset of the disease is insidious, occurring over several months or years; moreover, many cases are asymptomatic with palpable mass lesions present in $14-44 \%$ of patients. ${ }^{1}$ In symptomatic cases, the mass may be associated with pruritus, pain and a burning sensation and may be accompanied by exudate, haemorrhage, ulceration and invagination of the nipple. ${ }^{2}$ Upon exploration, lesions usually range in size from $3-15 \mathrm{~cm}$ and their appearance varies from small flaps to welldelimited erythematous and desquamative plaques with irregular borders. ${ }^{3}$

Patients with Paget's disease have a high incidence of associated mammary intraductal carcinomas; as such, mammography should be performed. ${ }^{3}$ A definitive diagnosis of Paget's disease is made via a large wedge biopsy that includes the nipple and areola. ${ }^{4}$ At the outset, this will reveal an in situ carcinoma of the galactophorous ducts that later extends until the epidermis where it causes diffuse modifications or nest-like clusters of cells, before subsequently breaking the wall of the conduits and invading the periglandular connective tissue. Paget cells can be seen in the galactophorous ducts and later in the epidermis while a chronic inflammatory infiltrate, vasodilatation and oedema is observed in the superficial dermis. ${ }^{2}$

The differential diagnosis of Paget's disease includes eczema, psoriasis, Bowen's disease, cutaneous melanomas, nodular localised cutaneous amyloidosis, benign intraductal papillomas, hyperkeratosis, erosive adenomatosis, impetigo, pityriasis versicolor, cutaneous squamous cell carcinoma in situ and benign familial pemphigus. ${ }^{1}$ Eczematous dermatitis of the nipple-with which Paget's disease can easily be confused-is usually bilateral, without accompanying induration and responds quickly to the application of topical corticosteroids. ${ }^{1}$ Treatment for Paget's disease is based on surgery, radiation therapy and chemotherapy, either alone or in combination. ${ }^{3}$

The incidence of axillary lymph node involvement and metastasis in Paget's disease is higher in patients with a palpable mass than in patients without a palpable mass. Patients with areolar changes only in the nipple and without a palpable mass usually have negative mammograms and less invasive carcinomas. ${ }^{3}$ Physicians should maintain a high level of suspicion of nipple-areola complex abnormalities since a superficial lesion reminiscent of Paget's disease may be the only sign of a more serious underlying neoplasm. ${ }^{5}$ Therefore, Paget's disease should be considered in cases of eczematous breast lesions that persist for more than three weeks despite topical treatment.

\section{References}

1. Casals-Felip R, Martin-Ezquerra G, Esgueva Pallares R, Corominas Torres JM. [Paget disease of the breast]. Med Clin (Barc) 2007; 129:440. doi: 10.1157/13110469.

2. Martín Pérez A, Rodríguez Nevado IM, Chaves Álvarez AJ, Salguero Bodes I. [Paget's disease of the breast]. Semergen 2008; 34:470-1. doi: 10.1016/S1138-3593(08)75210-9.

3. Muttarak M, Siriya B, Kongmebhol P, Chaiwun B, Sukhamwang N. Paget's disease of the breast: Clinical, imaging and pathologic findings - A review of 16 patients. Biomed Imaging Interv J 2011; 7:e16. doi: 10.2349/biij.7.2.e16.

4. Bijker N, Rutgers EJ, Duchateau L, Peterse JL, Julien JP, Cataliotti L. Breast-conserving therapy for Paget disease of the nipple: A prospective European Organization for Research and Treatment of Cancer study of 61 patients. Cancer 2001; 91:472-7. doi: 10.1002/1097-0142(20010201)91:3<472::AIDCNCR1024>3.0.CO;2-Q.

5. Lin $\mathrm{CH}$, Lee HS, Yu JC. Melanoma of the nipple mimicking Paget's disease. Dermatol Online J 2007; 13:18. 